\title{
An assessment of treatment compliance among patients on DOTS under revised national tuberculosis control programme in district Rewa, Madhya Pradesh, India
}

\author{
Neeraj Rai $^{1 *}$, S.S. Kushwah ${ }^{2}$, S.P. Singh ${ }^{2}$, Deepak Dubey ${ }^{3}$
}

\author{
${ }^{1}$ Department of Community Medicine, NSCB Medical College, Jabalpur, MP, India \\ ${ }^{2}$ Department of Community Medicine, S. S. Medical College, Rewa, MP, India \\ ${ }^{3}$ Department of Community Medicine, Jhalawar Medical College Jhalawar, Rajasthan, India
}

Received: 25 September 2015

Revised: 05 October 2015

Accepted: 19 October 2015

\section{*Correspondence:}

Dr. Neeraj Rai,

E-mail: dr_neeraj301@yahoo.co.in

Copyright: (C) the author(s), publisher and licensee Medip Academy. This is an open-access article distributed under the terms of the Creative Commons Attribution Non-Commercial License, which permits unrestricted non-commercial use, distribution, and reproduction in any medium, provided the original work is properly cited.

\section{ABSTRACT}

Background: India is the highest TB burden country in the world. In the year 2006, annual performance of revised national tuberculosis control programme (RNTCP) in India, in terms of cure rate of new smear positive patients was $84 \%$, default rate was $6.4 \%$ while in Madhya Pradesh it was $82 \%$ and $7.6 \%$ respectively. Rewa district have poor performance as compare to national level. Non-adherence with treatment has been recognized as an important factor responsible for low cure rate and high incidence of drug resistant TB. The objective of study was to find out the compliance rate with DOTS and associated factors responsible for non-compliance in the district.

Methods: The present observational study was carried out at fifteen selected DMC cum DOTS centers of Rewa district, M.P.

Results: Of the 337 patients interviewed, majority of patients $270(80.11 \%)$ complied and 67 (19.88\%) did not comply to treatment. The main reasons for non-compliance were false perception of having their disease cured because they felt well with initial treatment 26 (38.81\%), side effects of drugs 23 (34.33\%), anxiety of loss of wages 9 (13.43\%) and Migration of patients 7 (10.44\%).

Conclusions: Repeated counselling and motivation of noncompliant patients would be helpful to reduce noncompliance to treatment.

Keywords: Tuberculosis, DOTS, DMC, Compliance, Non-compliance, RNTCP

\section{INTRODUCTION}

Tuberculosis (TB) is a major cause of illness and death worldwide, especially in Asia and Africa. Globally, 9.2 million new cases and 1.7 million deaths from TB occurred in 2006, of which 0.7 million cases and 0.2 million deaths were in HIV-positive people. ${ }^{1}$

In India 1.8 million tuberculosis cases occur annually, accounting for one-fifth of the world's new TB cases and two-thirds of the cases in the South-East Asia Region.
This makes India the highest TB burden country in the world. In the year 2006, annual performance of revised national tuberculosis control programme (RNTCP) in India, in terms of cure rate of new smear positive patients was $84 \%$, default rate was $6.4 \%$ while in Madhya Pradesh it was $82 \%$ and $7.6 \%$ respectively. Rewa district have poor performance as compare to national level. ${ }^{2}$ Considering the above facts, this study was a small attempt to find out the compliance to DOTS and associated reasons responsible for non-compliance in the district. 


\section{METHODS}

The present observational study was carried out at 15 DMCs cum DOT centres of Rewa district from $1^{\text {st }}$ July 2007 to $30^{\text {th }}$ June 2008 .

In the study, out of 21 DMCs, 15 DMCs were selected by simple random method. These were DTC Rewa, District Hospital Rewa, Govindgarh, Raipur Karchulian, Gurh, Sirmaur, Baikunthpur, Mangawan, Gangeo, Mauganj, Hanumana, Naigarhi, Teonthar Chakghat and Jawa.

No sample size determination was done because all patients irrespective of age and sex, who were registered during the $3^{\text {rd }}$ Quarter of 2007 (from 1st July 2007 to $30^{\text {th }}$ September 2007) and also receiving drugs at these 15 DMCs cum DOT centres were included in this study.

Patients who were receiving treatment from other health centres (PHC, Sub health centres) where sputum microscopy facility was not available were excluded from the study. Patients who cannot be contacted at the recorded residential address even after two visits, MDR TB cases, Hospitalized patients and who were not consented to participate in the study were also excluded.

\section{Working definition of noncompliance}

Missing more than 2 constitutive weeks of DOTS was taken as non-compliance. ${ }^{3}$

During initial survey DOTS cum DMC centers wise list of all 381 registered patients was prepared from Tuberculosis Registers with the help of DTO and STS. Then initial survey was carried out from October 2007 to March 2008. Informed verbal consent of the patients was taken before interview. Patients were interviewed preferably at the DOTS centres and those who were missed at DOTS centres were interviewed at their home. During initial survey non-compliant patients were also interviewed and counselled at their home.

Follow-up survey was carried out after completion of therapy from March to June 2008. During March-April 2008 all Non-compliant patients (including those who were found non-adherent during initial survey) of Category-I and III were traced with help of STS and interviewed at their home to know the reason of noncompliance while patients of Category-II were interviewed in May-June 2008.

Collected data were analysed by using Graph Pad InStat3 software. The Chi-squire Test was used for statistical analysis.

\section{RESULTS}

Table 1: Distribution of patients according to their compliance to treatment.

\begin{tabular}{|llcc|}
\hline No. & Status & No. & $\%$ \\
\hline 1. & Compliance & 270 & 80.1 \\
\hline 2. & Non-compliance & 67 & 19.9 \\
\hline Total & & 337 & 100 \\
\hline
\end{tabular}

Out of total 381 registered patients only 337 patients could be interviewed despite of two visits of their home. Of these 337 interviewed patients, majority of patients $270(80.1 \%)$ complied, while $67(19.9 \%)$ patients did not comply with treatment.

Out 67 non-adherent patients, 51 were found noncompliant during the initial survey, of these 37 patients were retrieved on DOTS and completed treatment whereas 5 patients were taking treatments from private clinics (3 from registered practitioner, 2 from quacks), 4 were migrated and another 5 patients stopped treatments mainly due to side effects of drugs. During final survey 16 patients were found non-compliant to treatment, of these 4 patients retrieved on treatment by concerned STS but other 12 patients completely stopped treatment.

Table 2: Association of compliance with age of patients.

\begin{tabular}{|llllllll|}
\hline \multirow{2}{*}{ No. $\begin{array}{l}\text { Age } \\
\text { (Year) }\end{array}$} & \multicolumn{2}{l}{ Compliance } & \multicolumn{2}{l}{$\begin{array}{l}\text { Non- } \\
\text { Compliance }\end{array}$} & \multicolumn{2}{l|}{ Total } \\
\hline 1 & $<10$ & 04 & 80.0 & 01 & 20.0 & 05 & 1.5 \\
\hline 2 & $11-20$ & 28 & 77.7 & 08 & 22.3 & 36 & 10.7 \\
\hline 3 & $21-30$ & 113 & 88.3 & 15 & 11.7 & 128 & 37.2 \\
\hline 4 & $31-40$ & 66 & 75.9 & 21 & 24.1 & 87 & 25.8 \\
\hline 5 & $41-50$ & 27 & 65.9 & 15 & 34.1 & 42 & 12.2 \\
\hline 6 & $>50$ & 31 & 79.5 & 08 & 20.5 & 39 & 11.6 \\
\hline \multicolumn{2}{l}{ Total } & 270 & 80.1 & 67 & 19.9 & 337 & 100 \\
\hline
\end{tabular}

$\chi 2=12.924 ; \mathrm{P}=0.0241$, Significant

The study revealed that the compliance was maximum in the age group of $21-30$ years $(88.3 \%)$ and minimum in 41-50 years of age (65.9\%). The association of compliance with age is statistically significant $(\mathrm{p}=0.0241)$.

Compliance with treatment was more in female $(83.5 \%)$ as compared to male $(78.1 \%)$. However the association of compliance with sex was statistically not significant $(\mathrm{p}=0.231)$. 
Table 3: Association of compliance with sex of patients.

\begin{tabular}{|c|c|c|c|c|c|c|c|}
\hline \multirow{2}{*}{ No. } & \multirow{2}{*}{$\operatorname{Sex}$} & \multicolumn{2}{|c|}{ Compliance } & \multicolumn{2}{|c|}{ Non-Compliance } & \multicolumn{2}{|c|}{ Total } \\
\hline & & No. & $\%$ & No. & $\%$ & No. & $\%$ \\
\hline 1 & Male & 164 & 78.1 & 46 & 21.9 & 210 & 62.3 \\
\hline 2 & Female & 106 & 83.5 & 21 & 16.5 & 127 & 37.7 \\
\hline Total & & 270 & 80.1 & 67 & 19.9 & 337 & 100 \\
\hline
\end{tabular}

$\chi 2=1.432 ; \mathrm{P}=0.231$, Significant

Table 4: Association of compliance with education.

\begin{tabular}{|llllllll|}
\hline \multirow{2}{*}{ No. } & \multirow{2}{*}{ Education Status } & \multicolumn{2}{l}{ Compliance } & \multicolumn{2}{l}{ Non-compliance } & \multicolumn{2}{l|}{ Total } \\
\cline { 3 - 8 } & No. & $\%$ & No. & $\%$ & No. & $\%$ \\
\hline 1 & Illiterate & 37 & 59.7 & 25 & 40.3 & 62 & 18.4 \\
\hline 2 & Primary School & 62 & 81.6 & 14 & 18.4 & 76 & 22.6 \\
\hline 3 & Middle School & 49 & 89.1 & 6 & 10.9 & 55 & 16.3 \\
\hline 4 & High School & 49 & 80.3 & 12 & 19.7 & 61 & 18.1 \\
\hline 5 & Higher Secondary & 51 & 86.4 & 8 & 13.6 & 59 & 17.5 \\
\hline 6 & Graduate \& above & 22 & 91.7 & 2 & 8.3 & 24 & 7.1 \\
\hline Total & & 270 & 80.1 & 67 & 19.9 & 337 & 100 \\
\hline
\end{tabular}

$\chi 2=22.63 ; \mathrm{P}=0.0004$, Significant

Table 5: Association of compliance with religion of patients.

\begin{tabular}{|llllllll|}
\hline \multirow{2}{*}{ No. } & \multirow{2}{*}{ Religion } & \multicolumn{2}{c}{ Compliance } & \multicolumn{2}{l}{ Non-Compliance } & \multicolumn{2}{l|}{ Total } \\
\hline 1 & Hindu & No. & $\%$ & No. & $\%$ & No. & $\%$ \\
\hline 2 & Muslim & 255 & 82.0 & 56 & 18.0 & 311 & 92.3 \\
\hline Total & & 15 & 57.7 & 11 & 42.3 & 26 & 7.7 \\
\hline
\end{tabular}

$\chi 2=8.869 ; \mathrm{P}=0.0029$, Significant

Table 6: Association of compliance with occupation.

\begin{tabular}{|c|c|c|c|c|c|c|c|}
\hline \multirow{2}{*}{ No. } & \multirow{2}{*}{ Occupation } & \multicolumn{2}{|c|}{ Compliance } & \multicolumn{2}{|c|}{ Non-compliance } & \multicolumn{2}{|c|}{ Total } \\
\hline & & No. & $\%$ & No. & $\%$ & No. & $\%$ \\
\hline 1. & Unemployed & 41 & 89.1 & 05 & 10.9 & 46 & 13.6 \\
\hline 2. & Laborer / Daily wager & 94 & 68.6 & 43 & 31.4 & 137 & 40.7 \\
\hline 3. & Skilled Laborer & 05 & 71.4 & 02 & 28.6 & 07 & 2.1 \\
\hline 4. & Housewife & 88 & 89.8 & 10 & 10.2 & 98 & 29.1 \\
\hline 6. & Govt. Service & 08 & 88.9 & 01 & 11.1 & 09 & 2.7 \\
\hline 7. & Businessman & 14 & 82.4 & 03 & 17.6 & 17 & 5.0 \\
\hline 8. & Farmer & 18 & 85.7 & 03 & 14.3 & 21 & 6.2 \\
\hline 9. & Other* & 02 & 100 & 00 & 00 & 02 & 0.6 \\
\hline Total & & 270 & 80.1 & 67 & 19.9 & 337 & 100 \\
\hline
\end{tabular}

$\chi 2=21.22 ; \mathrm{P}=0.003$, Significant $*$ Priest and Cook

It was found that compliance was more in educated patients as compared to illiterate. Highest non-compliance was seen among illiterate $(40.3 \%)$ while lowest among patients who were educated up to graduate \& above $(8.3 \%)$. The association was statistically highly significant $(\mathrm{p}=0.0004)$.
It observed that majority of the patients studied were Hindus $311(92.3 \%)$. However compliance to treatment was also found to be more in Hindus (82\%) as compared to Muslims $(57.7 \%)$. The association was statistically significant $(\mathrm{p}=0.0029)$. 
Table 7: Association of compliance with socioeconomic status.

\begin{tabular}{|c|c|c|c|c|c|c|c|}
\hline \multirow{2}{*}{ No. } & \multirow{2}{*}{ Socioeconomic Class } & \multicolumn{2}{|c|}{ Compliance } & \multicolumn{2}{|c|}{ Non-compliance } & \multicolumn{2}{|c|}{ Total } \\
\hline & & No. & $\%$ & No. & $\%$ & No. & $\%$ \\
\hline 1. & Class-I & 12 & 85.7 & 02 & 14.3 & 14 & 4.2 \\
\hline 2. & Class-II & 26 & 83.9 & 05 & 16.1 & 31 & 9.2 \\
\hline 3. & Class-III & 38 & 80.9 & 09 & 19.1 & 47 & 13.9 \\
\hline 4. & Class-IV & 73 & 82.0 & 16 & 18.0 & 89 & 26.4 \\
\hline 5. & Class-V & 121 & 77.6 & 35 & 22.4 & 156 & 46.3 \\
\hline Total & & 270 & 80.1 & 67 & 19.9 & 337 & 100 \\
\hline
\end{tabular}

$\chi 2=1.407 ; \mathrm{P}=0.843$, Not Significant

Table 8: Association of compliance with presence of family history of tuberculosis.

\begin{tabular}{|llllllll|l|}
\hline \multirow{2}{*}{ No. } & \multirow{2}{*}{ Family History } & \multicolumn{2}{c|}{ Compliance } & \multicolumn{2}{l|}{ Non-compliance } & \multicolumn{2}{c|}{ Total } \\
\hline 1 & Present & No. & $\%$ & No. & $\%$ & No. & $\%$ \\
\hline 2 & Absent & 17 & 37.0 & 29 & 63.0 & 46 & 13.6 \\
\hline Total & & 253 & 86.9 & 38 & 13.1 & 291 & 86.4 \\
\hline
\end{tabular}

$\chi 2=62.308 ; \mathrm{P}=<0.0001$, Significant

Table 9: Association of compliance with history of addiction.

\begin{tabular}{|c|c|c|c|c|c|c|c|c|}
\hline \multirow{2}{*}{ No. } & \multirow{2}{*}{ Addiction } & & \multicolumn{2}{|l|}{ Compliance } & \multicolumn{2}{|c|}{ Noncompliance } & \multicolumn{2}{|c|}{ Total } \\
\hline & & & No. of cases & $\%$ & No. of cases & $\%$ & No. & $\%$ \\
\hline \multirow{4}{*}{1} & \multirow{4}{*}{ Smoking } & Yes & 57 & 62.6 & 34 & 37.4 & 91 & 27.0 \\
\hline & & No & 213 & 86.6 & 33 & 13.4 & 246 & 73.0 \\
\hline & & Total & 270 & 80.1 & 67 & 19.9 & 337 & 100 \\
\hline & & $\chi 2=23$ & 001, Significa & & & & & \\
\hline \multirow{4}{*}{2} & \multirow{4}{*}{ Alcohol } & Yes & 45 & 59.2 & 31 & 40.8 & 76 & 22.6 \\
\hline & & No & 225 & 86.2 & 36 & 13.8 & 261 & 77.4 \\
\hline & & Total & 270 & 80.1 & 67 & 19.9 & 337 & 100 \\
\hline & & $\chi 2=26$ & 001, Significa & & & & & \\
\hline \multirow{4}{*}{3} & \multirow{4}{*}{ Tobacco chewing } & Yes & 79 & 75.2 & 26 & 24.8 & 105 & 31.1 \\
\hline & & No & 191 & 82.3 & 41 & 17.7 & 232 & 68.9 \\
\hline & & Total & 270 & 80.1 & 67 & 19.9 & 337 & 100 \\
\hline & & $\chi^{2}=2.2$ & Not Significar & & & & & \\
\hline \multirow{4}{*}{4} & \multirow{4}{*}{ Others* } & Yes & 22 & 71.0 & 09 & 29.0 & 31 & 9.2 \\
\hline & & No & 248 & 81.0 & 58 & 19.0 & 306 & 90.8 \\
\hline & & Total & 270 & 80.1 & 67 & 19.9 & 337 & 100 \\
\hline & & $\chi^{2}=1.7$ & Not Significar & & & & & \\
\hline
\end{tabular}

*Nasmanjan; ganja smoking; opium and snuff

Compliance to DOTS was more among housewives $(89.8 \%)$ followed by unemployed $(89.1 \%)$ and patients having govt. service $(88.9 \%)$. Lowest compliance was observed in Labourer/daily wager (68.6\%). The association of compliance with occupation was statistically highly significant $(\mathrm{p}=0.003)$.

Compliance was maximum in patients belong to Class-I $12(85.7 \%)$ and minimum in Class-V, 121 (77.6\%). But there was no significant association between socioeconomic class and compliance to treatment.

Compliance was found to be more in patients with no history of tuberculosis in their family (86.9\%) as compare to patients with positive family history of tuberculosis (37\%). The association was statistically highly significant $(\mathrm{p}<0.0001)$. 
Table 10: Association of compliance with different category of treatment.

\begin{tabular}{|llllllll|}
\hline \multirow{2}{*}{ No. } & Category & Compliance & \multicolumn{2}{c}{ Non-compliance } & \multicolumn{3}{c|}{ Total } \\
\cline { 3 - 8 } & No. & $\%$ & No. & $\%$ & No. & $\%$ \\
\hline 1. & Category-I & 125 & 81.7 & 28 & 18.3 & 153 & 45.4 \\
\hline 2. & Category-II & 46 & 66.7 & 23 & 33.3 & 69 & 20.5 \\
\hline 3. & Category-III & 99 & 86.1 & 16 & 13.9 & 115 & 34.1 \\
\hline Total & & 270 & 80.1 & 67 & 19.9 & 337 & 100 \\
\hline
\end{tabular}

$\chi 2=10.650 ; \mathrm{P}=0.004$, Significant

Table 11: Distribution of noncompliant patients according to reasons for non-compliance $(\mathrm{n}=67) *$.

\begin{tabular}{|lll|ll|}
\hline No. & Reasons* & $\begin{array}{l}\text { Stopped DOTS } \\
\text { Temporarily } \\
(\mathbf{n = 4 1})\end{array}$ & $\begin{array}{l}\text { Stopped DOTS } \\
\text { Permanently } \\
(\mathbf{n = 2 6 )}\end{array}$ & $\begin{array}{l}\text { Total no. of patients } \\
(\mathbf{n = 6 7 )}\end{array}$ \\
\hline 1 & It was difficult to take so many pills & $03(60.0 \%)$ & $02(40.0 \%)$ & $05(7.5 \%)$ \\
\hline 2 & Another Doctor told me to stop treatment & $00(00 \%)$ & $03(100 \%)$ & $03(4.5 \%)$ \\
\hline 3 & Moved away from treatment Centre (migration) & $03(42.9 \%)$ & $04(57.1 \%)$ & $07(10.4 \%)$ \\
\hline 4 & Work related / loss of daily wages & $02(22.2 \%)$ & $07(77.8 \%)$ & $09(13.4 \%)$ \\
\hline 5 & Felt better (improvement in condition) & $17(65.4 \%)$ & $09(34.6 \%)$ & $26(38.8 \%)$ \\
\hline 6 & Due to side effects of drugs & $09(39.1 \%)$ & $14(60.9 \%)$ & $23(34.3 \%)$ \\
\hline 7 & Due to other illness & $05(100 \%)$ & $00(00 \%)$ & $05(7.5 \%)$ \\
\hline 8 & Domestic problem & $05(71.4 \%)$ & $02(28.6 \%)$ & $07(10.4 \%)$ \\
\hline 9 & Dissatisfaction with DOT provider & $01(25.0 \%)$ & $03(75.0 \%)$ & $04(6.0 \%)$ \\
\hline 10 & Others** & $07(77.8 \%)$ & $02(22.2 \%)$ & $09(13.4 \%)$ \\
\hline
\end{tabular}

*Multiple reasons; ** Social-stigma, no improvement in health condition, dissatisfaction with frequent visits and timing of center, advice of quack, denial of diagnosis.

Compliance was observed significantly higher among non-smoker $(86.6 \%)$, and non-alcoholic (86.2\%). while patients who had no habit of tobacco chewing and any other type of addictions showed (82.3\%) and (81\%) compliance respectively to treatment.

Compliance was maximum in patients who were taking treatment of category-III $(86.1 \%)$ followed by category-I $(81.7 \%)$ and least in patients who were taking treatment of category-II (66.7\%). The association was also statistically significant $(\mathrm{p}<0.05)$.

Most common reason for non-compliance was false perception of having their disease cured because they felt well with initial treatment $26(38.8 \%)$ followed by side effects of drugs 23 (34.3\%).

\section{DISCUSSION}

In the study out of 337 , majority of patients $270(80.1 \%)$ were complied with treatment and 67 (19.9\%) patients did not comply. Jaggarajamma et al observed similar non-compliance rate of $20 \%$ in their study in tiruvallur district of Tamilnadu. ${ }^{4}$ While Mahesh Kumar et al in 2002 reported $89.4 \%$ compliance rate while Neeraj Pandit et al in 2006 observed $93 \%$ compliance rate and $7 \%$ default rate. ${ }^{3,5}$ This may be due to difference in working definitions of noncompliance.
Patients in the 21-30 years age group were mostly compliant $(88.3 \%)$ to treatment while middle aged patients (41-50years) were least compliant to DOTS. The association of compliance with age is statistically significant $(\mathrm{p}=0.0241)$. Similar observation that noncompliance was maximum in middle age group were also reported by Sophia et al $65.2 \%$ But Menzis et al found that older subjects were less compliant. ${ }^{6,7}$

In the present study compliance was higher among female $83.5 \%$ than male $78.1 \%$. In other words noncompliance was more prevalent among male patients (21.9\%). The association of compliance with sex was not statistically significant. Mahesh Kumar et al and Polo Fri et al also reported higher percentage of noncompliance among female. ${ }^{3,8}$

It is evident from study that compliance rate was significantly higher among well-educated patients as compared to illiterate. Highest non-compliance was seen among illiterate $(40.3 \%)$. Probably the illiterate patients did not know the consequences of irregular treatment. So for improving compliance to DOTS, patients should be educated about various aspects of disease, DOTS and importance of completion of treatment. Gopi et al. in their study in South India observed that non-adherence to DOTS was higher among illiterate $(39 \%)$ as compare to literates $(30 \%) .{ }^{9}$ The study revealed statistically higher compliance rate in Hindus (82\%) as compared to 
Muslims (57.7\%). Probably Muslims were more illiterate and belonging to lower/poor class of society. Similar observations reported by Mahesh Kumar et al in their study in Lucknow District. ${ }^{3}$

The compliance rate was also significantly higher among housewives $(89.8 \%)$ followed by unemployed $(89.1 \%)$ and government servant $(88.9 \%)$. While Labourer/daily wager showed least compliance to DOTS $(68.6 \%)$. It may be due to that the labourers were unable to visit frequently for getting drug because of loss of daily wage on day of drug collection and poor knowledge regarding various aspects of DOTS. Other authors in their study found higher default rate among employed than unemployed. ${ }^{4}$ The results from another study by Santha et al suggested that compliance was almost equal in employed and unemployed. ${ }^{10}$

In our study we did not found any significant association between socioeconomic class of patients and compliance to treatment. However noncompliance was highest among patients belonging to lower socioeconomic classV (22.4\%) Probably due to most of the patients of lower socioeconomic class were daily wager and illiterates. Ashry Gad et al in their study in Alexandria also revealed the same fact that the socio economics status had no significant association with compliance to treatment. The findings are concordance with present study. ${ }^{11}$ But Chatterjee et al reported that income showed inverse association with drug default. ${ }^{12}$ Johansson et al in their study in Vietnam had observed that patient's economic situation is an important determinant of compliance and noncompliance. ${ }^{13}$ Noncompliance to DOTS was significantly higher among alcoholic and smokers. Similar observations were recorded by Burman et al in 1997 and Jakubowiak et al in $2007 .^{14,15}$

The study revealed significant association between noncompliance to DOTS and positive family history of tuberculosis. O'Boyale et al also reported that noncompliance was higher in patients who had family history of TB. ${ }^{16}$

The study shows that compliance was more in patients suffering from pulmonary tuberculosis $(80.6 \%)$ than extra pulmonary tuberculosis $(77.6 \%)$ whereas Santha et al in their study observed that compliance was higher in patients with extra pulmonary Tuberculosis. ${ }^{10}$

Non Compliance with treatment was maximum in category-II $(33.3 \%)$ followed by category-I $(18.3 \%)$ and least in category-III $(13.9 \%)$. It is because most of patients of category-II $23(33.3 \%)$ have habit to default. The association of compliance and treatment category was statistically significant $(\mathrm{p}=0.004)$. Jaggarajamma et al in their study in tiruvallur district observed 19\%, 38\%, $11 \%$ default rate among patients from category-I, II and III respectively. ${ }^{4}$ Sophia et al in Bangalore also found that $45.2 \%$ default rate among re-treatment cases were significantly higher as compared to new patients of category-I $(25.4 \%){ }^{6}$

In the present study majority of patients gave more than one reason for non-adherence to treatment. The main reasons for non-compliance were false perception of having their disease cured because they felt well with initial treatment $26(38.8 \%)$, side effects of drugs 23 $(34.3 \%)$, fear of loss of wages $9(13.4 \%)$, Migration of patients $7(10.4 \%)$. Migration was mainly on occupational ground. Beside these 7 (10.4\%) patients showed noncompliance due to domestic problems and difficulty in taking so many tablets was given as a reason for dropping out from treatment by $5(7.5 \%)$ patients. However $5(7.5 \%)$ patients interrupted treatment due to other illness. Dissatisfaction with DOT provider accounts for noncompliance in $4(6 \%)$ patients. Few patients 3 (4.5\%) stopped treatment permanently on the advice of private doctors and they were started to taking treatment at private clinics.

Juvekar et al similarly reported that reason of default to treatment were felt better $27 \%$, health services related problem $17 \%$, side effects of drugs $10 \% .{ }^{17}$ Jaggarajamma et al found that Intolerance to drugs $42 \%$, migration $29 \%$, symptoms free $20 \%$, work related problems $15 \%$, treatment elsewhere $13 \%$ and domestic problems $8 \%$ were major factors for non-adherence to treatment in their study. ${ }^{4}$ Suhadev et al observed that main reasons of noncompliance were unwillingness of treatment $33 \%$, adverse reactions of treatment $27 \%$, work related problems $23 \%$, migration $22 \%$, addiction $12 \%$, taking treatment elsewhere $7 \%$ and felt well $3 \% .^{18}$ Jacintha D'Souza reported that side effects of drugs was major reason for non-compliance to treatment in $43 \%{ }^{19}$ However Tekle et al observed that inadequate knowledge about duration of treatment and medication side effects were significantly associated with defaulting. ${ }^{20} \mathrm{We}$ inferred that repeated counselling and motivation of noncompliant patients would be helpful to reduce noncompliance with treatment.

\section{ACKNOWLEDGEMENTS}

Authors are extremely thankful to Dr. G.W. Lanke (former associate professor, Statistic) and other faculty members of the department for their invaluable guidance and suggestions. We are also grateful to Dr. B. L. Mishra, DTO and other RNTCP staff of district Rewa for providing necessary assistance for carrying out the study. Our heartiest Thanks to all the study subjects for their cooperation.

Funding: Grant was provided by RNTCP, District Rewa (MP), India

Conflict of interest: None declared

Ethical approval: The study was approved by the Institutional Ethics Committee 


\section{REFERENCES}

1. World Health Organization. Global TB Report. Geneva; WHO 2008:1-20.

2. TB India. RNTCP Status report: I am stopping TB. Central TB Division, Directorate General Health Services, MOHFW Nirman Bhawan. New Delhi. 2008:10-95.

3. Kumar M, Singh JV, Srivastava AK, Verma SK. Factors affecting the non-Compliance in Directly Observed Short Course Chemotherapy in Lucknow District. Indian Journal of Community Medicine. 2002;27(3):114-7.

4. Jaggarajamma K, Sudha G, Chandrasekaran V, Nirupa C, Thomas A, Santha T, et al. Reasons for noncompliance among patients treated under revised national tuberculosis control programme (RNTCP), Tiruvallur District, South India. Indian J Tuberc. 2007;54:130-5.

5. Pandit N, Choudhary SK. A study of treatment compliance in Directly Observed Therapy for tuberculosis. Indian journal of community Medicine. 2006;31(4):241-3.

6. Sophia V, Balasangameswara VH, Jagannatha PS, Saroja VN, Kumar P. Defaults among tuberculosis patients treated under DOTS in Bangalore city: a search for solution. Indian $\mathrm{J}$ Tuberc. 2003;50(4):185-95.

7. Menzis D, Adhikari N, Tannenbaum T. Patient characteristics associated with failure of tuberculosis prevention. Int Tuberc lung Diseases. 1996;77(4):308-14.

8. Polo Friz H, Kremer L, Acosta H, Abdala O, Canova S, Rojo S, et al. Treatment with Tuberculo static drugs: compliance at a general hospital. Revista de la facultad de clcncias medicalUniversidad National de cardoba. 1997;55(1-2);215.

9. Gopi PG, Vasantha M, Muniyandi M, Chandrasekharan V, Balasubramaniam R. Risk factor for Non adherence to directly observed treatment (DOTs) in a rural tuberculosis unit, South India. Indian J Tuberc. 2007;54(3):66-70.

10. Santha T, Garg R, Frieden TR, Chandrasekaran V, Subramani R, Gopi PG. Risk factors associated with default, failure and death among tuberculosis patients treated in a DOTS programme in Tiruvallur District, South India, 2000. Int J of Tuberc Lung Dis. 2002;6(9):730-38.

11. Gad A, Mandil AMA, Sherif AAR, Gad ZM, Sallam S. Compliance with antituberculosis drugs among tuberculosis patients in Alexandria, Egypt. East Medit health J. 1997;3(2):244-50.

12. Chatterjee P, Banerjee B, Dutt, Pati RR, Mullick AK. A comparative evaluation of factors and reasons for defaulting in tuberculosis treatment in the states of West Bengal, Jharkhand and Arunachal Pradesh. Ind J Tub. 2003;50(3):17-21.

13. Johansson E, Diwan VK, Huang ND, Ahlberg BM. Staff and patients attitudes to tuberculosis and compliance with treatment: an exploratory study in a district in Vietnam. Tuber Lung Dis. 1996;77(2):178-83.

14. Jakubowiak WM, Bogorodskaya EM, Borisov SE, Danilova ID, Kourbatova EV. Risk factors associated with default among new pulmonary TB patients and social support in six Russian regions. Int. J. Tuberculosis and Lung Disease. 2007;11(8):46-53.

15. Burman WJ, Cohn DL, Rietmeijer CA, Judeen FM, Sbarbaro JA, Reves RR, et al. Non-compliance with directly observed therapy for Tuberculosis: Epidemiology and effect on the outcome of treatment. Chest. 1997;111(5):1168-73.

16. O’Boyle SJ, Power JJ, Ibrahim MY, Watson JP. Factor affecting patient's compliance with antituberculosis chemotherapy using the directly observed treatment, short-course strategy (DOTS). Int J Tuber Lung Dis. 2002;6(4):307-12.

17. Juvekar SK, Morankar SN, Dalal DB, Rangan SG, Khanvilkar SS, Vadair AS, et al. Social and operational determinants of patient behaviour in lung tuberculosis. Indian J Tub.1995;42:87.

18. Mohanarani S, Ganapathy S, Sivasubramaniarrr S,Santha Devi T. A retrospective study of "noncompliant" patients in controlled clinical trials of short course chemotherapy. Indian $\mathbf{J}$ Tub. 1995;42:221.

19. D'Souza J. Effect of intensive health education on adherence to treatment in sputum positive pulmonary tuberculosis patients. Ind $\mathbf{J}$ Tub. 2003;50:33-8.

20. Tekle B, Mariam DH, Ali A. Defaulting from DOTS and its determinants in three districts of Arsi Zone in Ethopia. Int $\mathrm{J}$ Tuberc Lung Dis. 2002;6(7):573-9.

Cite this article as: Rai N, Kushwah SS, Singh SP, Dubey D. An assessment of treatment compliance among patients on DOTS under revised national tuberculosis control programme in district Rewa, Madhya Pradesh, India. Int J Community Med Public Health 2015;2:373-9. 